\title{
Mortality Trend of Hodgkin Lymphoma in Ecuador from 2000 to 2019
}

\author{
David Garrido ${ }^{\text {* }}$, Manuel Granja ${ }^{2}$, Johanna Rojas ${ }^{3}$
}

\author{
${ }^{1}$ Hematology Department, Hospital de Clinicas “Dr. Manuel Quintela”, Universidad de la Republica, Montevideo, URUGUAY \\ ${ }^{2}$ Hematology Department, Hospital Carlos Andrade Marín, Quito, ECUADOR \\ ${ }^{3}$ Hematology Department, Hospital Metropolitano, Quito, ECUADOR \\ *Corresponding Author: david_labinmuno@hotmail.com
}

Citation: Garrido D, Granja M, Rojas J. Mortality Trend of Hodgkin Lymphoma in Ecuador from 2000 to 2019. Electron J Gen Med. 2021;18(1):em272. https://doi.org/10.29333/ejgm/9359

\section{ARTICLE INFO}

Received: 3 Aug. 2020

Accepted: 20 Sep. 2020

\section{ABSTRACT}

Introduction. Globally, the incidence of Hodgkin lymphoma (HL) increased from 1990 to 2017, presenting two incidence peaks regarding age, at 20-39 years, and 60 years or more. However, there is limited information about the mortality of this disease in the Ecuadorian population. This study aims to present the mortality trend of HL in Ecuador from 2000 to 2019.

Methods. We performed an observational study, reporting the crude death rates by $\mathrm{HL}$ in the Ecuadorian population from 2000 to 2019, and its mortality trend analysis. Data were extracted from governmental databases published by the Ecuadorian National Institute of Statistics and Census (INEC).

Results. From 2000 to 2019, INEC registered 862 deaths of patients with HL. From them, 355 (41.18\%) were female, and $699(81.09 \%)$ resided in urban areas, with an average age of 54.61 years. During the period studied, the mortality rates by $\mathrm{HL}$ in Ecuador presented a significant increasing trend $(\mathrm{p}=0.037)$, in which 2019 and 2018 were the years with the highest death rate ( 0.38 by 100,000 inhabitants), whereas 2001 and 2007 had the lowest death rate ( 0.20 by 100,000 inhabitants). Regarding age, we found a bimodal distribution of cases with two peaks in the 2nd and 7 th decades of life.

Conclusion. In this study, we found the highest mortality rate of HL in 2018 and 2019, with a significant increasing trend since 2000. Regarding age, we found two highest mortality peaks, which correspond to the 2nd and 7th decades of life, similar to other studies in the region.

Keywords: Hodgkin lymphoma, mortality, epidemiology, Ecuador

\section{INTRODUCTION}

Hodgkin lymphoma (HL) represents a family of lymphoproliferative neoplasms characterized by the presence of tumoral Hodgkin/Reed-Sternberg cells in nearly $95 \%$ of cases [1].

Globally, the incidence of $\mathrm{HL}$ cases increased from 72,937 in 1990 to 101,133 in 2017, displaying two incidence peaks regarding age, at 20-39 years, and in patients aged 60 years or more [2].

In Latin America, $\mathrm{HL}$ incidence rates have shown a bimodal pattern and presented an increasing trend, which varied 7 -fold in males and 11-fold in females, with the highest agestandardized incidence rate in Argentina, Brazil, Costa Rica (males), Cuba (males) and Uruguay (females). In contrast, the lowest rates in Bolivia and El Salvador [3]. Additionally, in the region, the age-standardized mortality rates increased by 4 fold in males and 6-fold in females [3].

Currently, the mortality of $\mathrm{HL}$ is lower than previous decades, which may be associated with improvements in diagnosis and new therapeutic strategies [4]. However, this may not be the case for developing countries. In this context, knowledge of mortality trends is relevant to know how the disease affects our population.

Considering that there is limited information published regarding the mortality of $\mathrm{HL}$ in the Ecuadorian people, this study aims to present the mortality trend of $\mathrm{HL}$ in Ecuador from 2000 to 2019.

\section{METHODS}

We performed an observational and cross-sectional study, reporting the crude death rates by $\mathrm{HL}$ in the Ecuadorian population from 2000 to 2019, and its mortality trend analysis.

\section{Data Obtention}

Data were extracted from governmental databases published each year by the Ecuadorian National Institute of Statistics and Census (INEC). This information is presented in SPSS format and is freely available on the web site of the institution.

The datasets analyzed during the current study are available on the (Ecuador en Cifras: Camas y Egresos Hospitalarios) page, (https://www.ecuadorencifras.gob.ec/ camas-y-egresos-hospitalarios/). 


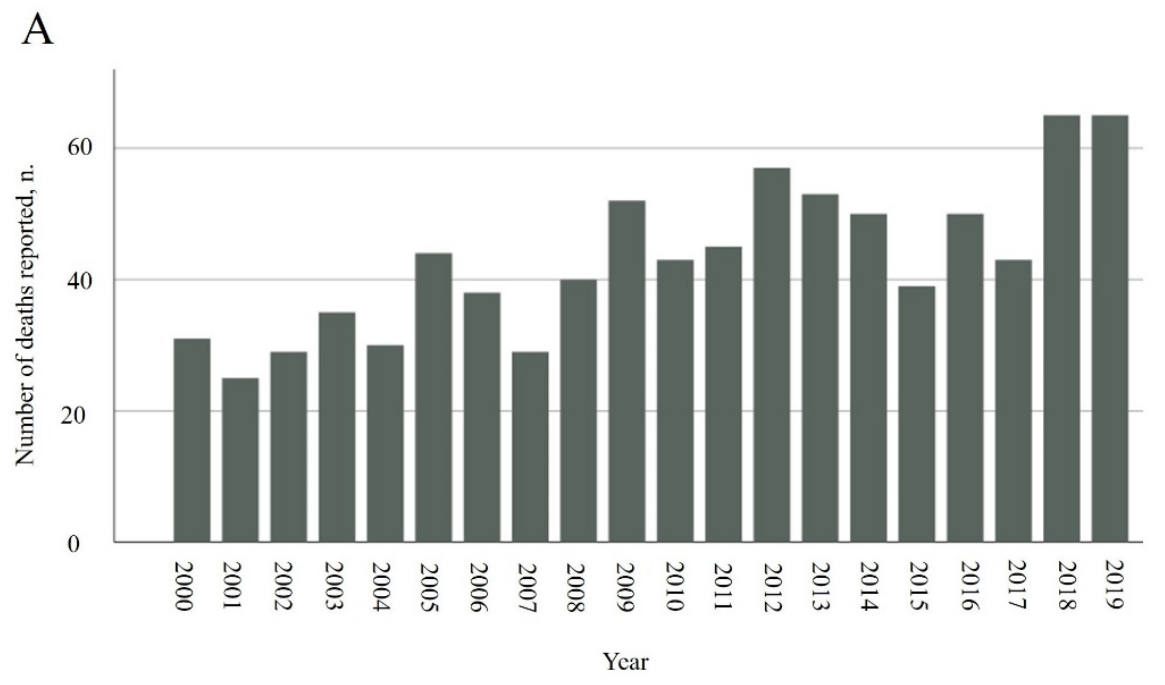

B

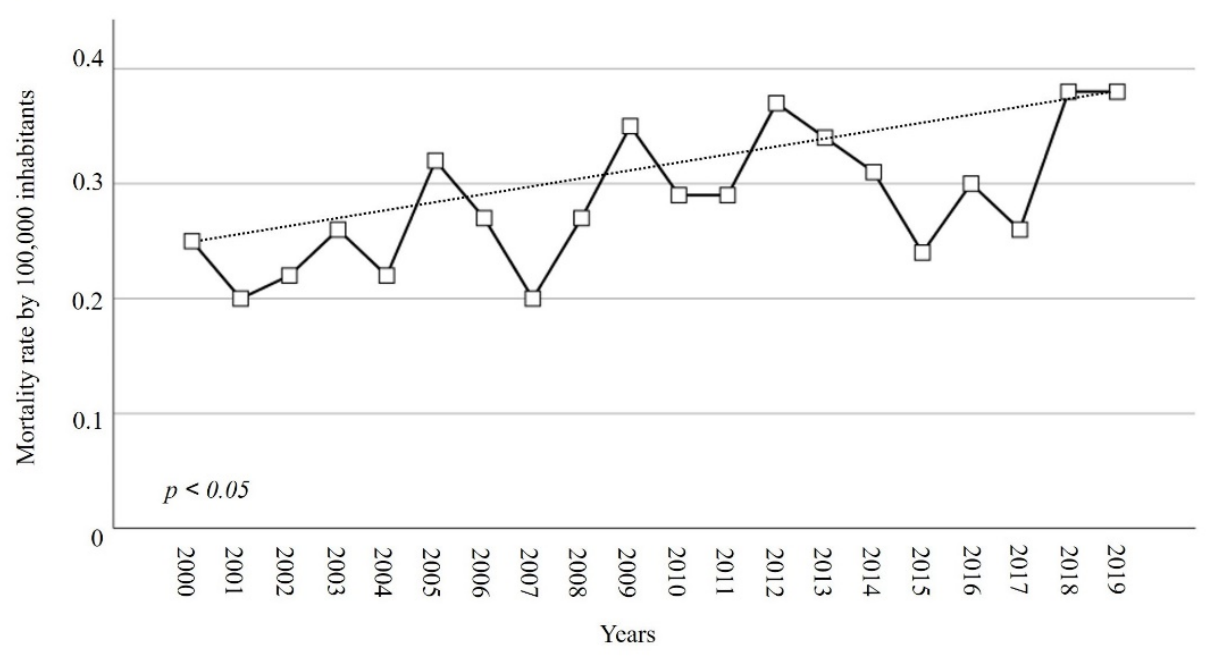

Figure 1. A, Number of deaths of patients with Hodgkin lymphoma in Ecuador, by year or report; B, Mortality trend of Hodgkin lymphoma in Ecuador

As the SPSS record has information on all the deaths reported in the country each year, we used the ICD-10 code C81 to find the patients affected by HL.

For this study, we included the following information: the total number of deaths reported by $\mathrm{HL}$ each year, the total number of inhabitants each year, and demographic characteristics including age, sex, area of residence (urban or rural), and ethnic group. We did not report the subtype of lymphoma due to the majority of cases being registered as unspecified $\mathrm{HL}$.

\section{Statistical Analysis}

We performed the statistical analysis using the software SPSS V.23 and Excel 2013. Qualitative variables were presented as percentages and quantitative variables as average values with standard deviation.

To calculate the crude mortality rate, we used the equation:

Crude death rate

$=\frac{\text { Total number of deaths in a calendar year by } H L}{\text { Estimated mid }- \text { year population that year }} \times 10^{5}$
To analyze the mortality trend significance, we used chi square test.

\section{RESULTS}

From 2000 to 2019, the INEC registered 862 deaths of patients diagnosed with $\mathrm{HL}$. Of them, 507 (58.82\%) were male, $355(41.18 \%)$ female, and 699 (81.09\%) resided in urban areas, with an average age of 54.61 years. The ethnic group was reported between 2009 and 2019, with mestizo ethnicity as the most frequently present.

The years with the highest number of deaths were 2019 and 2018, with 65 cases. In contrast, 2001 had 25 deaths reported (Figure 1A). Similarly, 2019 and 2018 were the years with the highest death rate $(0.38$ by 100,000 inhabitants), whereas 2001 and 2007 had the lowest death rate $(0.20$ by 100,000 inhabitants).

During the period studied, we found that mortality rates by $\mathrm{HL}$ in Ecuador presented a significant increasing trend using chi square test $(p<0.05)$ (Figure 1B). 


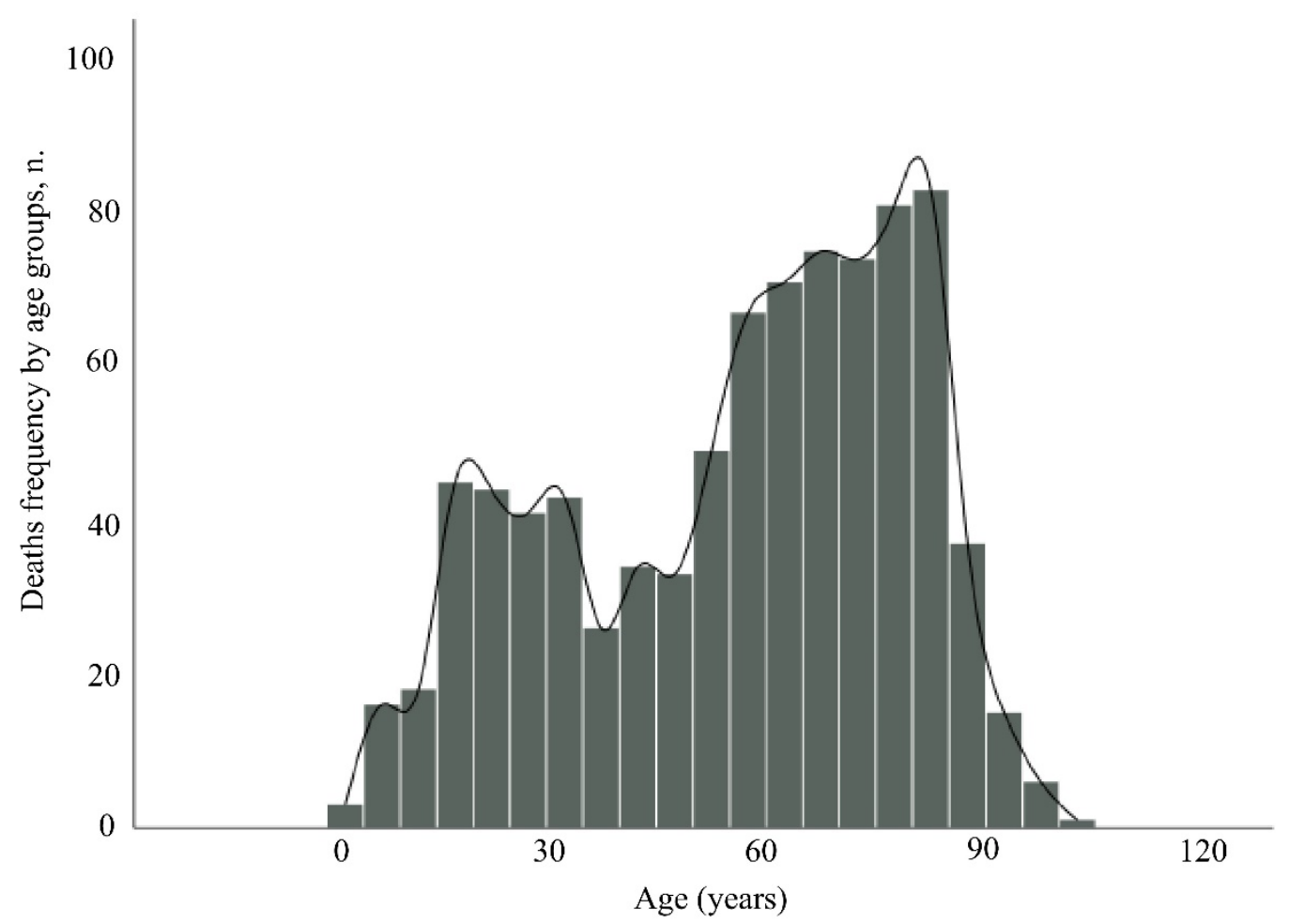

Figure 2. Deaths frequency of patients with Hodgkin lymphoma, by age

Additionally, regarding the age groups affected, we found a bimodal distribution of cases with two peaks in the 2 nd and 7 th decades of life (Figure 2).

\section{DISCUSSION}

In this study, we found the highest mortality rate of $\mathrm{HL}$ in 2018 and 2019, with a significant increasing trend since 2000, which is congruent with the findings of Kusminsky, et al. [3].

Regarding age, we found two peaks of highest mortality, which corresponds to the 2 nd and 7th decades of life, similar as the incidence pattern reported among Hispanics in the United States: with one peak at ages 20-29 years, and a second peak in the elderly (70-79 years) [5].

\section{Higher Morality in Elderly Patients}

In this study, we observed that the mortality peak in elderly patients is significantly higher than the younger population. This finding may be explained as $\mathrm{HL}$ in elderly patients has a different presentation compared with the younger people. As an example, the more predominant histology is mixed cellularity. Also, more frequently older patients are diagnosed with advanced-stage HL, B Symptoms, and has a low tolerance to treatment due to pre-existing comorbidities, which results in dose reductions, therapy delays, and excessive treatmentrelated toxicity and mortality [6].

\section{Increasing Trend in HL Mortality}

An increasing mortality trend may rely on the fact that $\mathrm{HL}$ diagnosis improved during the last decades, and consequently, the register of deceased patients [7]. However, it is necessary to conduct more studies in the Ecuadorian population to compare how the more recent therapeutical approaches benefit the overall survival.

\section{Limitations}

This study had limitations, such as it is based in a secondary source, which does not exhibit all the clinical features for each patient and consequently, risk associations cannot be established. Also, national registries had limitations, which in the Ecuadorian population include inequalities by sex, geographical areas, and quality of the mortality registry [8].

\section{CONCLUSION}

In this study, we found the highest mortality rate of $\mathrm{HL}$ in 2018 and 2019, with a significant increasing trend since 2000. Regarding age, we found two highest mortality peaks, which correspond to the 2 nd and 7 th decades of life, similar to other studies in the region. We believe that the increasing trend in mortality is associated with the growing availability of diagnosing methods. However, more studies are needed to clarify this finding.

Author contributions: All authors have sufficiently contributed to the study, and agreed with the results and conclusions.

Funding: No funding source is reported for this study.

Declaration of interest: No conflict of interest is declared by authors.

\section{REFERENCES}

1. Wang HW, Balakrishna JP, Pittaluga S, Jaffe ES. Diagnosis of Hodgkin lymphoma in the modern era. $\mathrm{Br} \mathrm{J}$ Haematol. 2019;184(1):45-59. https://doi.org/10.1111/bjh.15614 PMid: 30407610 PMCid:PMC6310079 
2. Zhou L, Deng Y, Li N, Zheng Y, Tian T, Zhai Z, et al. Global, regional, and national burden of Hodgkin lymphoma from 1990 to 2017: estimates from the 2017 Global Burden of Disease study. J Hematol Oncol 2019;12(1):107. https://doi.org/10.1186/s13045-019-0799-1 PMid:31640759 PMCid:PMC6805485

3. Kusminsky G, Abriata G, Forman D, Sierra MS. Hodgkin lymphoma burden in Central and South America. Cancer Epidemiol 2016;44(Suppl 1):S158-S167. https://doi.org/ 10.1016/j.canep.2016.07.016 PMid:27678318

4. Koshy M, Fairchild A, Son $\mathrm{CH}$, Mahmood U. Improved survival time trends in Hodgkin's lymphoma. Cancer Med 2016;5(6):997-1003. https://doi.org/10.1002/cam4.655 PMid:26999817 PMCid:PMC4924356

5. Evens AM, Antillón M, Aschebrook-Kilfoy B, Chiu BC. Racial disparities in Hodgkin's lymphoma: a comprehensive population-based analysis. Ann Oncol 2012;23(8):2128-37. https://doi.org/10.1093/annonc/mdr578 PMid:22241896
6. Böll B, Görgen $H$. The treatment of older Hodgkin lymphoma patients. $\mathrm{Br} J$ Haematol 2019;184(1):82-92. https://doi.org/10.1111/bjh.15652 PMid:30407626

7. Shanbhag S, Ambinder RF. Hodgkin lymphoma: A review and update on recent progress. CA Cancer J Clin 2018;68(2):116-32. https://doi.org/10.3322/caac.21438 PMid:29194581 PMCid:PMC5842098

8. Peralta A, Benach J, Borrell C, Espinel-Flores V, CashGibson L, Queiroz BL, et al. Evaluation of the mortality registry in Ecuador (2001-2013) - social and geographical inequalities in completeness and quality. Popul Health Metr 2019;17(1):3. https://doi.org/10.1186/s12963-0190183-y PMid:30922340 PMCid:PMC6437878 